\title{
A Perspectiva ético-estética da educação: uma proposta de educação do olhar para a emancipação e a autonomia
}

\author{
Ingrid Gayer Pessi, Donizeti Pessi \\ Ana Luiza Ruschel Nunes
}

\section{Resumo}

O trabalho se sustenta a partir de estudos sobre uma educação ético-estética, por meio de investigações teóricas, que tratam da formação do olhar como processo de novas descobertas e propostas de visão de mundo e da sociedade, por intermédio da interpretação sugerida pela arte-educação. $\mathrm{O}$ principal referencial para a pesquisa foram as obras de Theodor Adorno, bem como, estudos a respeito de seus escritos. A intenção da pesquisa, de caráter qualitativo-bibliográfico e revisão de literatura, é provocar discussões acerca da formação universitária e da relação professor-aluno - que deveria indicar nova orientação do olhar, a partir da beleza proporcionada no ambiente de sala de aula, para a beleza do mundo [espaço por excelência onde acontece a educação integral do homem]. O que conduz, ainda, ao entendimento de que a experiência estética pode promover o surgimento de sujeitos emancipados e autônomos - capazes de interpretar o mundo e a vida, experienciados pela arte, educação e a beleza no e do mundo. Palavras-chave: Arte. Educação. Ética. Estética. Olhar.

\section{The ethics-aesthetic perspective of education: a proposal to educate the eyes to emancipation and autonomy}

\section{Abstract}

The work is based on studies on an aesthetic-ethical education, through theoretical investigations, which deal with the formation of the look as a 
process of new discoveries and proposals of vision of the world and of society, through the interpretation suggested by art-education. The main reference for the research were the works of Theodor Adorno, as well as, studies on his writings. The intention of the research, with a qualitative-bibliographic character and literature review, is to provoke discussions about the university formation and the teacher-student relationship - which should indicate a new orientation of the look, from the beauty provided in the classroom environment, to the beauty of the world [space par excellence where the integral education of man happens]. This also leads to the understanding that aesthetic experience can promote the emergence of emancipated and autonomous subjects - capable of interpreting the world and life experienced by art, education and beauty in the world. Key-words: Art. Education. Ethic. Aesthetics. Look.

\section{La perspectiva ética-estética de la educación: una propuesta de educación de la mirada hacia la emancipación y la autonomía}

\section{Resumen}

El trabajo se sustenta a partir de estudios sobre una educación ético-estética, por medio de investigaciones teóricas, que tratan de la formación de la mirada como proceso de nuevos descubrimientos y propuestas de visión de mundo y de la sociedad, a través de la interpretación sugerida por el arte-educación. El principal referencial para la investigación fueron las obras de Theodor Adorno, así como estudios sobre sus escritos. La intención de la investigación, de carácter cualitativo-bibliográfico y revisión de literatura, es provocar discusiones acerca de la formación universitaria y de la relación profesor-alumno - que debería indicar nueva orientación de la mirada, a partir de la belleza proporcionada en el ambiente de aula, para la belleza del mundo [espacio por excelencia donde sucede la educación integral del hombre]. Lo que conduce, aún, al entendimiento de que la experiencia estética puede promover el surgimiento de sujetos emancipados y autónomos - capaces de interpretar el mundo y la vida, experimentados por el arte, la educación y la belleza en el mundo.

Palabras clave: Arte. Educación. Ética. Estética. Mira. 


\section{Considerações iniciais}

O trabalho realizado percorre propostas educacionais que orientam para novas oportunidades de olhares sobre o mundo externo - a realidade cotidiana de todo e qualquer indivíduo inserido na educação. A pesquisa apresenta uma abordagem bibliográfica e qualitativa, com a intenção de perpassar a ideia de realidade, entendendo-a como uma possibilidade de educação ético-estética e de pensar uma educação do olhar para que se possa pensar a beleza no mundo, bem como, a beleza do mundo - intra e extras-sala de aula.

Para isso, pensa-se, ainda, na direção que a arte, em sua condição fenomenológica - que deveria surgir já na relação professor -aluno e na formação docente - pode possibilitar uma visão mais sensível do mundo, dos fatos e da vida, contra a insensibilização do homem contemporâneo. Uma educação pautada na sensibilidade à beleza, forma e conduz o indivíduo para conceber-se como um sujeito sensível ao mundo - na relação intra e interpessoal.

Assim, discute-se a formação humana integral, considerando a necessidade da arte como elemento fundante da interpretação da educação ético-estética que orienta o sujeito dessa educação para a autonomia e emancipação - condições da construção social, que também orientam o olhar a superar as questões imediatistas do mundo hodierno, ultrapassando - e não ignorando - a perspectiva conteudista da educação, e avançando para a leitura e a vivência experiencial do sensível, da estética, da beleza, da ética da educação, da aula e do conhecimento por meio da sensibilidade humana.

Para tanto, precisamos pensar numa arte-educação que proporcione, ainda, a olhar para a beleza contra a barbárie, a do passado para que não se repita no presente, a do presente para que não perdure no futuro. Por isso, a educação ético-estética, que conduz o olhar para a beleza e interpretação crítica do mundo e da realidade social, no ensino superior deve assumir, ainda mais, o compromisso de assegurar tais propostas em outros níveis e ambientes onde a educação se faz acontecer. 
O trabalho foi dividido em seções que pretendem realizar uma apresentação da sala de aula como espaço privilegiado de vivência da ética, da arte, da beleza, e da criticidade por ela proporcionada. E, continua propondo uma reflexão sobre o lugar da beleza na educação, discutindo a postura do homem contemporâneo, um ser insensibilizado - num constante estado momentâneo de ter, não inclinado à compaixão, "negando" a si mesmo e a sua condição de ser-com-o-outro e ser-no-mundo.

Assim sendo, verifica-se a necessidade de uma nova "educação do olhar" - como forma de resgate da alma para a emancipação do sujeito, bem como, a superação da banalização do mal e do bem, e ainda, contra a barbárie social.

\section{A sala de aula: uma vivência}

A rotina é um caminho para o desencanto, contrário ao que a sala de aula deve despertar. E as vítimas dessa atrocidade são os próprios professores, principalmente quando eles deixam de observar o que significa um ambiente de sala de aula.

Quando o professor entra em uma sala de aula - e isso não deve ser ignorado -, entra em cena, pois todos os olhares se voltam para ele, olhares esses de alunos que estão com todas as atenções voltadas para o "ator" em questão; o que não significa que os alunos sejam apenas receptores, mas sim, observadores de todos os sinais emitidos pelo professor, isto quer dizer que não se satisfazem com palavras como a única forma de comunicação.

A sala de aula constitui um microcosmo dentro do imenso universo onde a vivência da aula, como possibilidade de educação do olhar, se faz presente e se efetiva. Ao retomar a história da educação, é possível perceber que uma preocupação e discussão devem ser levantadas sem hesitação: quem tem necessidade da aula? Com esse questionamento, pode-se vislumbrar, e até vasculhar, as lembranças promovidas pela história, onde se verificará que a aula era uma necessidade de satisfação do professor, e não para atender a uma necessidade de aprendizagem do aluno. 
O aluno sempre foi "marcado" pelos seus professores, com o que eles fizeram para que a aula correspondesse aos anseios de visão de mundo, bem como, por aquilo que eles não fizeram para que os olhares vislumbrassem a educação também fora da escola, em relação ao mundo, à sociedade e a si mesmo. Outras vezes, o aluno não consegue se lembrar do que eles [os professores] fizeram, por não tê-lo instigado ao incômodo da aprendizagem, muitas vezes nem mesmo da disciplina imposta pelo método de ensino.

Quanto ao que diz respeito do ensino superior, nem sempre o acadêmico se lembra das aulas bem elaboradas pelos professores, mas lembra de que, na sala de aula, o micropalco que prepara para atuação no mundo, cenas fortes e impressionantes foram bem executadas, o que não limitava a um olhar pequeno, mas um olhar que nos possibilitasse enxergar a arte da vivência no mundo.

A sala de aula, nesse sentido, é como um filme, que sempre remete o espectador àquelas cenas que lhe foram caras e significativas. Isso não significa que aquilo que o professor faz em sala de aula seja uma encenação, mas é sim uma atuação com significados. Assim, a sala de aula constitui o espaço por excelência de uma vivência ética, pois, em encenação do professor, é exigida uma postura de compromisso e cor-responsabilidade diante daqueles que são, naquele momento, espectadores do mundo apresentado por aquele professor.

Desse modo, o rosto do professor passa a ser o meio de veiculação, pois “[...] é o rosto que desvenda o mistério do olhar. [...] O rosto do professor revela ao aluno o segredo do seu olhar" (ALVES, 2015).

Essa exposição indica a necessidade de um entendimento a respeito do professor, que é simples transmissor de um conteúdo programático - que talvez constitua, simplesmente, um pretexto para que a educação aconteça, pois o professor educa ainda mais para o encantamento com a vida e para a vida. Isso revela que a relação ensino-aprendizagem, a relação professor-aluno, também abre a educação do olhar, que dá condições de ensinar a ver o mundo - como o lugar por excelência da educação - com os próprios 
olhos, e autonomamente. Assim, o aluno é levado a observar que o educador, ao orientar para a visão de mundo, deixa inquestionáveis impressões no microuniverso da consciência de cada um.

A dimensão ético-estética da prática educativa em sala de aula sempre é considerada, e os professores não podem esquecer-se de verificar, e constatar, que muitas de suas atitudes em aula podem educar, mas também deseducar aqueles que se encontram num processo. Desse modo, “[...] o professor precisa tomar consciência de que suas atitudes, por mais naturais ou espontâneas que sejam, são sempre atitudes educativas ou deseducativas" (OLIVEIRA, 2005, p. 6).

A sala de aula é, por excelência, o ambiente de aprendizado da ética e da beleza. $\mathrm{Na}$ aula são cruzados olhares éticos-estéticos, a partir das relações intra e interpessoais, e delas o surgimento da relação da beleza com a educação e com o mundo. É o espaço onde os alunos dispõem-se às atitudes éticas e estéticas, para depositarem seus olhares sobre o mundo e a vivência social. Ela [a sala de aula] constitui-se, ainda, num espaço de promoção às inquietações frente à banalização do mal.

$\mathrm{Na}$ sala de aula, local onde se deve experienciar a beleza, é também o habitat natural da relação professor-aluno, pois o professor pode ensinar a enxergar o mundo e a vida de modo diferente. $\mathrm{O}$ que significa escapar aos limites dos programas conteudistas para avançar para a vida em ação e beleza.

A sala de aula, não como mero espaço de conteúdo acadêmico e científico, torna-se, também, o ambiente singular de vivência ético-estética; sendo assim, um espaço de educação para a consciência da vida no mundo - desse modo, a escola da vida e a escola do conhecimento científico encontram-se numa única realidade cósmica- e nesse espaço o mestre da ciência torna-se, igualmente, o mestre da vida.

Questionamentos podem ser lançados: o que a crise ética e estética de nosso mundo contemporâneo tem a interrogar sobre os "seus" professores? Que face estética do mundo a educação oferece ao aluno contemporâneo? Observando essas questões, 
pode-se considerar que o ser humano, como produtor de cultura, precisa entender que valores estéticos (visão de mundo e educação do olhar) e éticos - relações inter e intrapessoais (visão micro e macrocósmica) não se dissociam.

A postura do professor, nesse mundo contemporâneo de perda de valores, deve ser, antes de tudo, uma postura de quem educa para expectativas, esperando melhores frutos, para a observação de horizontes, para a percepção e consciência dos fatos e de todos aqueles fenômenos que se manifestam em nosso mundo - sobre o qual a educação age. E experienciar o mundo é, igualmente, ser sensível a ele, permitindo que algo aconteça e transforme em favor do próprio mundo.

Educar o olhar é estar atento às necessidades dos tempos, saber decifrá-las e promover possibilidades e habilidades educativas.

\section{O lugar da beleza na educação: valores e desva- lores}

Os valores educacionais enfrentam crise quando há, igualmente, crise na educação do olhar e, por conseguinte, na percepção do lugar da beleza na educação. Pois, com a crise do olhar, os valores culturais presentes na vida e no mundo, passam a ser simples produtos carregados de variáveis que não representam atitudes afirmativas, o que se remete na distinção entre o que é tradicional e o que é arcaico - entre aquele valor que deve ser mantido, protegido, guardado e transmitido e aquele que precisa ser abandonado.

Uma das faces da crise no mundo é a vivência da insensibilização do homem contemporâneo, que revela sua incapacidade "[...] de se compadecer do que lhe acontece entorno, ensimesmado que está, numa tentativa de puxar o olhar para além do que se apresenta como fato inquestionável e implacável, como se somente um caminho estivesse disponível" (AMORIM, CASTANHO, 2008, p. 95).

Assim, a crise de valores pode ser constatada pela confusão, bem como pela banalização do entrave entre valores e contravalores, pois o homem perdeu de vista a necessidade que tem da beleza. 
Essa crise afeta direta e indiretamente o campo da educação e obscurece o olhar.

Como proposta de saída da crise de valores - sobre a relação educação, estética e ética - pode-se perguntar: por que falar com beleza e da beleza no ambiente de sala de aula? Esse questionamento impulsiona a refletir a respeito do homem contemporâneo, já mencionado, ser insensibilizado, num constante estado momentâneo do ter. Esse homem não inclinado à compaixão, perdendo de vista a sua condição de ser-com-o-outro e ser-no-mundo.

Assim sendo, volta-se à necessidade de uma nova educação do olhar, de um resgate da alma, porque o homem é, por excelência um ser estético e ético, por isso, a nenhum outro ser cabe a educação - o homem tem necessidade da beleza, e o mundo é o lugar onde essa necessidade é satisfeita, pela educação que, por sua vez, é o lugar onde a beleza deveria ser experienciada, como experiências encarnada no sujeito, e não destruídas pela mecanicidade do movimento rotineiro. Porque, “[...] ensinar é um exercício de imortalidade. De alguma forma continuamos a viver naqueles cujos olhos aprenderam a ver o mundo pela magia da nossa palavra. $\mathrm{O}$ professor, assim não morre jamais" (ALVES, 2015).

Por isso, tanto a educação quanto o professor precisam estar atentos ao fenômeno da banalização - esvaziamento e minimização - do olhar, à linguagem do tempo hodierno, aos desafios que questionam se os valores são descartáveis, e que impulsionam a perguntar: o que significa educar? Educar para quê? Como educar? Pois, os alunos, cada vez mais, estão interessados nas imediatas ofertas; assim, os professores encantados com a educação devem gerar o encantamento com o mundo, evitando, no aluno, a vulnerabilidade e a perda de sua identidade enquanto sujeito da educação e do mundo.

Assim, pode-se afirmar que o que a educação espera do ato de educar é sua serenidade, seriedade, habilidades éticas e estéticas para enfrentar as rápidas mudanças que o mundo contemporâneo sofre, sem perder de vista a orientação e o rumo da beleza no educar. Esse é um desafio que revela que a tarefa de educar não é ilusão; 
e por isso, é necessário que o professor comece a educar o olhar na sua sala de aula, fazendo dela um ambiente privilegiado de vivência ética e estética (OLIVEIRA, 2005).

Segundo Nietzsche (2004), a primeira tarefa da educação é ensinar a ver; isso revela que por meio do olhar o aluno entra em contato com a beleza e o fascínio do mundo. O olhar precisa ser educado para a ascensão do encantamento e do conhecimento do mundo e da vida.

Dessa forma, a educação/aula assume o lugar de resgate do homem sensível a si, ao outro, à natureza, ao mundo: lugar de sensibilização do mundo - onde está a beleza, como fruto objetivo da racionalidade humana, bem como, via de interioridade, onde a relação intersubjetiva e a relação entre sujeito e objeto acontecem.

A arte de olhar transforma os olhos da relação professor-aluno em um espelho pelo qual o indivíduo reconhece aspectos do seu sentir - qualidade da vida prática. Pela arte o homem é convidado a olhar o mundo, mais profunda e detalhadamente; porque a arte educa para a ampliação da compreensão do mundo, não como uma arte educativa, mas a arte educa como arte, isto é, a arte educa sem a preocupação de educar por ser ela mesma cultura.

Pode-se entender, então, que o trabalho docente é sim uma arte que se iguala à arte que educa para ampliar a compreensão de mundo, além da racionalização predominante no mundo ocidental. Que educa para conhecer mais sobre o mundo, mais sobre as pessoas e sobre si mesmo por meio do que artistas e arte nos apresentam (LOPONTE, 2006).

É possível constatar que a educação deveria ser o lugar em que a beleza possibilitaria novas percepções diárias acerca da vida prática, isto é, sobre a eticidade da vida e do mundo.

\section{A estetização da educação}

O olhar e a dedicação do professor à educação não podem ser reduzidos a exames que desconsideram intrínseca relação entre a vida, o mundo e a cultura como um todo amplo e diverso. Consi- 
derando a educação como a arte de se expressar e de ver o mundo, a quem se proponha a desenvolver o tema não pode desconsiderar o valor do conhecimento cultural mais amplo como recorrente para quem pretende ser um formador.

O indivíduo para ser professor e se emancipar precisa se libertar do imediatismo das relações, e fazer uso das propostas da beleza autêntica para caracterizar um desenvolvimento histórico a ser superado. Mas isso, sem emancipação da alma do sujeito, na atual circunstância da educação é como celebrar a morte da estetização do mundo e da educação, permitindo sua absorção pelo sistema (ADORNO, 1999).

Acrescenta-se, ainda, que existe certa desvalorização pela profissão de professor que é ratificada até mesmo por quem se propõe a ser formador de professores. Por isso, a proposta é de reagir às constatações apresentadas com reflexões embasadas em experiências culturais, estéticas e éticas vivenciadas, que flexibilizam o conhecimento da sociedade e do mundo em detrimento àquelas verdades consideradas absolutamente dogmatizadas (ADORNO, 1999).

A realidade da educacional precisa ser entendida como um veículo da estetização da configuração social. E o professor seria um modelo e espelho da condição emancipatória do sujeito com olhar forte sobre a fraqueza dos desvalores.

Pode-se observar que onde falta a educação do olhar e estética da educação, a emancipação, e a educação enquanto proposta emancipatória, passa a ser um simples jogo de sensações. Para que a educação proceda é preciso uma democracia efetiva e para isso acontecer é necessário que a sociedade seja emancipada pela arte. E o processo mais complicado está em nós mesmos, de nos adaptarmos à autonomia. Talvez a escola não esteja propondo a vivência das experiências, e sim repetir as experiências existentes.

Uma característica bem relevante para entender melhor o processo de emancipação pela educação pode estar relacionada à capacidade de compreensão, sobre a própria identidade individual e como isso pode ser utilizado na coletividade. De nada serve ser 
representante amorfo em um coletivo, é a capacidade de intervenção crítica e consciente, bem como de condução do olhar para ver a condição autônoma do conhecimento que poderá colaborar para as discussões emancipatórias na sociedade.

A humanidade precisa superar a barbárie e a própria banalização da educação, e isso é questão de sobrevivência. A educação não deve estimular a competição, ou somente preparar o indivíduo para o mundo do trabalho, e sim apresentar reflexões transparentes com uma finalidade humana (ADORNO, 1999).

Então, é necessário entender que a educação deve estar fundamentada nas questões e condições das ações humanas. É preciso que haja entendimento e respeito na educação, bem como, as condições humanas de compreender a ética, a moral e, principalmente, trabalhar contra a violência em favor da beleza. Assim, a emancipação, pode ser alcançada se for verdadeira para quem se proponha aplicá-la e para os que a recebem. E o movimento precisa ser recíproco.

A educação contra a barbárie constitui, ao mesmo tempo, a manifestação imediata da necessidade de conduzir o olhar para o encantamento e a beleza, algo que é próprio do instinto humano, e a instância própria para o seu apaziguamento.

A educação, como expressão artística, não pode perder sua credibilidade deixando-se moldar conforme as propostas da Indústria Cultural, para não se tornar mais um produto de mercado, nem mais um motivo de status. Delineia-se, assim, cada vez mais o fato que o homem busca na arte e na beleza a identidade perdida pela influência da cultura contemporânea que o rege. Pois, "séria é a vida, alegre é a arte" (ADORNO, 2001, p. 15).

\section{Estética versus barbárie}

A preocupação central na temática educacional é o combate contra a barbárie. E, para falar sobre a educação contra a barbárie, é necessário elucidar a conceitualização do termo barbárie. 
Suspeito que a barbárie existe em toda a parte em que há uma regressão à violência física primitiva, sem que haja uma vinculação transparente com objetivos racionais na sociedade, onde exista, portanto a identificação com a erupção da violência física. Por outro lado, em circunstâncias em que a violência conduz inclusive a situações bem constrangedoras em contextos transparentes para a geração de condições humanas mais dignas, a violência não pode sem mais nem menos ser condenada como barbárie (ADORNO, 1999, p. 159).

Essa educação pode fazer as barbáries do passado não se repetirem no presente e no futuro. Essa preocupação seria como se as gerações seguintes aprendessem com o que já ocorreu nos tempos atuais e não se deixassem ser levadas por esse sistema; o intuito seria que [as futuras gerações] não repetissem a barbárie social do individualismo, tão presente nos dias atuais.

Adorno se mostra assombrado com o fato que uma educação que faça que Auschwitz não se repita não tem merecido muita atenção; e ainda afirmou que tais "[...] monstruosidades não calaram fundo nas pessoas, e isso é sintoma da persistência da possibilidade de que se repita no que depender do estado de consciência e de inconsciência das pessoas" (ADORNO, 1999, p. 119). As pessoas, de certa forma, se tornaram apáticas aos acontecimentos transcorridos em Auschwitz.

Qualquer debate acerca de metas educacionais carece de significado e importância frente a essa meta: que Auschwitz não se repita. Ela foi a barbárie contra a qual se dirige toda a educação. Fala-se da ameaça de uma regressão à barbárie. Mas não se trata de uma ameaça, pois Auschwitz foi a regressão; a barbárie continuará existindo enquanto persistirem no que têm de fundamental as condições que geram esta regressão (ADORNO, 1999, p. 119).

A educação tem significado exclusivamente como educação conduzida a uma autorreflexão crítica, crítica essa que faça Auschwitz não se repetir (ADORNO, 1999). 


\section{A arte como educação}

A arte é, para Adorno, uma experiência que fornece um conhecimento para aquele que entra em contato com ela, porém enfatizando-se sempre a questão racional acerca da arte.

Se a arte fosse pura intuição, ela limitar-se-ia à mera empiria, da qual, segundo Adorno, ela procura desviar-se. O mimetismo da arte só sobrevive pela sua antítese, pelo momento racional. É por isso que "A arte é a intuição de algo não-intuitivo, é semelhante ao conceito sem conceito.” A arte se opõe ao conceito; mas, para isso, necessita dele (LOUREIRO, 2011).

A arte sugere o conhecimento da realidade visto que abstrai dela a inspiração necessária para tomar forma, inspiração essa abstraída em particular da sociedade, para que possa, por meio do olhar e da criticidade por ela transmitida, transformá-la. Por isso, da mesma forma que a educação, a arte remete para o universal, aqui percebido como a coletividade que, no entanto, não sacrifica, tampouco reprime o particular em detrimento de uma ordem dominadora.

Um dos grandes subsídios oferecidos pela arte à educação diz respeito ao abalo que o conhecimento não-conceitual artístico causa ao conhecimento em sua intenção de entender os fatos, o que é fenomenicamente demonstrável. Assim, a arte leva a educação a almejar o ideal, aquilo que faz a mediação entre a condição histórica de horror e uma educação na qual seja resguardado um lugar da beleza para a esperança (LOUREIRO, 2011).

Central nas antinomias atuais é o fato de que a arte deve e pretende ser utopia, e tanto mais decididamente quanto a relação real das funções impede a utopia; e que ela, porém, para não trair a utopia pela aparência e pela consolação, não tem o direito de ser utopia (ADORNO, 1970, p. 45).

A dimensão estética da educação sugere o conhecimento macrocósmico que se inspira na necessidade de tomar forma, inspiração essa abstraída em particular da sociedade e do mundo, para que possa, por meio do encantamento e da beleza por ela transmitida, transformá-la. Por isso, da mesma forma que a educação, 
a arte remete para o universal, aqui percebido como a coletividade que, no entanto, não sacrifica, tampouco reprime o particular em detrimento de uma ordem dominadora.

A arte possui uma relação com a verdade, da mesma forma que a educação tem a revelar sobre o mundo do conhecimento: a educação a arte e a filosofia convergem para um mesmo lugar no seu conteúdo: desdobram-se progressivamente para o desvelamento do mundo (ADORNO, 2001). E, "a arte, enquanto forma de conhecimento, recebe todo seu material e suas formas da realidade, especialmente do meio social, para, assim, poder transformá-lo" (ADORNO, 2001, p. 13), a partir de uma racionalidade crítica acerca dos fatos, nesse meio, transcorridos. Por exemplo, quando Picasso elabora Guernica, ele faz sua obra espelhando-se nos horrores percebidos em virtude da guerra, visando gerar em seus apreciadores um sentimento de reprovação e busca de superação daquela barbárie, por meio de uma racionalização crítica.

E é na alegria que o encantamento do mundo, pela educação, se liberta do aprisionamento causado pela Indústria Cultural, e tem a possibilidade de levar o indivíduo a uma auto-transcendência, para que se liberte das ideologias impostas e do individualismo exacerbado e se torne um conhecedor da condição humana, com senso crítico em vista dos fatos transcorridos à sua volta, perdendo o sentimento de apatia, convertendo-o em empatia. Porém, a alegria não pode ser entendida como uma alegria despreocupada, mas sim como uma alegria contextualizada que leve à reflexão (ADORNO, 2001).

A arte, que não é mais possível se não for reflexiva, deve renunciar por si mesma à alegria.a afirmativa que depois de Auschwitz não é mais possível escrever poesia, não deve ser cegamente interpretada, mas com sua certeza depois que Auschwitz se tornou possível e que permanece possível no futuro previsível, a alegria despreocupada da arte não é mais concebível (ADORNO, 2001, p. 13).

Porém, a alegria não pode ser entendida como uma alegria despreocupada, mas sim como uma alegria contextualizada que leve à reflexão. 


\section{Considerações finais}

O homem é um ser estético, e por ser, também o único ser que precisa ser educado, por conseguinte tem necessidade da beleza, beleza essa que o conduz à interpretação vivenciada do mundo - o lugar, por excelência onde acontece a educação, como formação humana integral.

Por isso, a aula/educação passa a constituir o "habitat natural" da relação professor/aluno - momento quando beleza pode, e deve ser experenciada - como experiências encarnadas ao sujeito, e não destruídas pela mecanicidade do movimento rotineiro.

A educação/aula é o "espaço de sensibilização do mundo", e constitui, ainda, o lugar de resgate do homem sensível a si, ao outro, à natureza, ao mundo: onde está a beleza. E onde a dimensão ético-estética da educação, da aula, da vida assume a beleza, presente no olhar do homem que se dispõe à educação, como fruto da racionalidade humana.

Assim sendo, a beleza objetivada no olhar, e encarnada na interioridade do sujeito, o lança, igualmente, à de relação intersubjetiva e à relação entre sujeito e objeto, sujeito e mundo, sujeito e sociedade, sujeito e vida.

Desse modo, a arte, como espelho, pelo qual o homem reconhece aspectos do seu sentir e a qualidade da vida prática, presta-se como educação que prepara para a superação da banalização do sujeito objetivado pelo sistema - nas palavras de Adorno: objetivado pela Indústria Cultural - que minimiza a sensibilidade do sujeito e a sensibilização social.

Pela arte o homem é convidado a olhar o mundo, a sociedade e a vida, mais profunda e detalhadamente. Por isso, ela - a arte - educa o olhar ético-esteticamente para a ampliação da compreensão do mundo, permitindo a si mesma educar como arte, e não simplesmente como arte educativa. 


\section{Referências}

ADORnO, T. W. A arte é alegre? In: Teoria Crítica, Estética e Educação. Piracicaba: UNIMEP, 2001.

. Educação e Emancipação. Tradução Wolfgang Leo Maar. São Paulo: Paz e Terra, 1999.

Mínima Moralia. Trad.: Artur Morão. Lisboa: Edições 70, 1951.

Teoria Estética. Lisboa: Edições 70, 1970.

. Teoria Estética. In: LOUREIRO, Robson. Filosofia e Educação: Elementos de estética em Adorno. Disponível em: <http://www.ufsm.br/gpforma/ 2senafe/PDF/012e2.pdf> Acesso em 8 ago. 2011.

ADORNO, Theodor; HORKHEIMER Max. Dialética do esclarecimento. Trad.: Guido Antonio de Almeida. Rio de Janeiro: Zahar, 2010.

ALVES, R. Educar o Olhar. Disponível em: http:/ /iberdade-cultural.blogspot. com.br/2014/04/educar-o-olharpor-rubem-alves.html. Acesso em 4 nov. 2015.

AMORIM, V. M.; CASTANHO, M. E. Da Dimensão Estética da Aula ou Lugar da Beleza na Educação. In: VEIGA, I. P. A. (Org.). Aula: Gênese, dimensões, princípios e práticas. Campinas: Papirus, 2008.

ARZUA, Glauce. Reificação e Autonomia: a dupla face da razão na estética musical de Adorno. In: Teoria Crítica, Estética e Educação. Piracicaba: UNIMEP, 2001.

LOPONTE, L. G. ENTREVISTA, concedida por correspondência eletrônica, à pesquisadora Verussi de Melo Amorim, em 20 de maio de 2006.

LOUREIRO, Robson. Filosofia e Educação: Elementos de estética em Adorno. Disponível em: <http://www.ufsm.br/gpforma/2senafe/PDF/012e2.pdf> Acesso em 28 jun. 2011.

Da Teoria Crítica de Adorno ao Cinema Crítico de Kluge: educação, história e estética. Tese de doutorado. Florianópolis: UFSC, 2006, p. 142. Tese [Doutorado] - Programa de Pós-Graduação em Educação, Universidade Federal de Santa Catarina, Florianópolis, 2006. 
NIETZSCHE, F. Escritos sobre Educação. Rio de Janeiro: Ed. PUC-Rio; São Paulo: Loyola, 2004.

OLIVEIRA, Newton de. Educação: Pensamento e Sensibilidade. In: Teoria Crítica, Estética e Educação. Piracicaba: UNIMEP, 2001.

OLIVEIRA, P. E. SALA DE AULA: espaço de vivência ética. In: Educação Marista. Ano V - número 10. Curitiba: CEMEP, 2005, p. 5-11.

Submetido em: 18-3-2018

Aceito em: 31-3-2018 